\title{
Metodología para el análisis de la accesibilidad tecnológica de las personas con discapacidad: Triangulación y elaboración de indicadores
}

\author{
Miguel A. V. Ferreira* \\ Mario Toboso Martín** \\ Francisco Patricio Pedraza***
}

Resumen. La accesibilidad tecnológica de las personas con discapacidad es abordada exclusivamente a partir de la concepción y perspectiva de los expertos, sin tener en cuenta a los/as usuarios/as. El presente trabajo tiene como objetivo subsanar ese déficit, tratando de desarrollar un instrumento de investigación útil el diseño tecnológico y la mejora en la accesibilidad, incorporando, para ello, un estudio en profundidad de la relación entre las personas con discapacidad y la tecnología. Denominamos a dicha metodología proMITIA (-propuesta de una- Metodología de Investigación Triangular para la elaboración de Indicadores de Accesibilidad). La misma comporta tres fases de desarrollo: una primera basada en cuestionarios exploratorios; una segunda que aplica técnicas de investigación cualitativa articuladas de manera triangular; por último, la codificación de la información mediante un conjunto de indicadores de accesibilidad.

Palabras clave: accesibilidad tecnológica, personas con discapacidad, identificación de barreras, triangulación metodológica, indicadores de accesibilidad.

\section{Methodology for de analysis of disabled peoble technological accessibility: Triangulation and indicators making}

\begin{abstract}
The approach to the technological accessibility of disabled people is based only on the experts' conceptions and perspective, without users' contribution. The objective of this paper is offer a solution to this deficit, developing a research device which is useful for the technological design and for the improvement of accessibility. A deep study of the relations between disabled people and technology is introduced. We name this technology "proMITIA" [pro-TRiMA] (-A proposal of a- Triangular Research Methodology for the elaboration of Accessibility Indicators). This methodology entails three development phases: a first one, based on exploratory questionnaires; a second one which applies qualitative research techniques articulated in a triangular mode; and finally, an information coding through a set of accessibility indicators.
\end{abstract}

Keywords: technological accessibility, disabled peoble, barriers detection, methodological triangulation, accesibility indicators.

* Universidad Complutense de Madrid

mavferre@ucm.es

** Consejo Superior de Investigaciones Científicas

mario.toboso@csic.es

3 Universidad Complutense de Madrid

patriciolapalma@yahoo.com 
Sumario. 1.Introducción. 2. Consistencia y coherencia metodológica de proMITIA. 3. Identificación de las barreras en el acceso de las personas con discapacidad al uso de tecnologías. 3.1. Técnicas cuantitativas. 3.2. Técnicas cualitativas. 4. Elaboración de los indicadores de accesibilidad y barreras. 5. Aplicación de la metodología proMITIA (fase preliminar). 6. Conclusiones. Bibliografía.

Cómo citar: V. Ferreira, M. A., Toboso Martín, M., Patricio Pedraza, F., «Metodología para el análisis de la accesibilidad tecnológica de las personas con discapacidad: Triangulación y elaboración de indicadores», en Cuadernos de Gobierno y Administración Pública 4-1, 59-87.

\section{Introducción ${ }^{1}$}

Las personas con discapacidad son objeto de múltiples procesos de exclusión y discriminación social (Abberley, 1987, 2008; Barnes, 1991; Liberty, 1994; Rodríguez Caamaño y Ferreira, 2006; Manase, 2009), entre los cuales se sitúa su capacidad de acceso a la tecnología(Fisher, 2010; Sheldon, 2001, 2003; Ferreira y Díaz, 2009; Chicote, Díaz y Ferreira, 2014). De hecho, la accesibilidad tecnológica de las personas con discapacidad es actualmente, además de un tema de debate y una preocupación creciente para los expertos en el desarrollo de tecnologías (particularmente de aquellas que tienen que ver con el acceso a la información, vía web, a través de los distintos dispositivos que lo permiten), una cuestión de suma importancia en los planes de intervención desarrollados a partir de directrices públicas, tanto a nivel europeo como nacional ${ }^{2}$.

En general, la accesibilidad tecnológica es abordada exclusivamente a partir de la concepción y perspectiva de los expertos, sin tener en cuenta a los/as usuarios/as, las personas con discapacidad, sus preocupaciones, sus expectativas, sus necesidades concretas ${ }^{3}$.

La metodología que proponemos tiene como objetivo subsanar ese déficit, tratando de desarrollar un instrumento de investigación que produzca información relevante para el diseño tecnológico y la mejora en la accesibilidad, incorporando, para ello, un estudio en profundidad de la relación entre las personas con discapacidad y la tecnología, entre el uso efectivo y el diseño. Denominamos a dicha metodología proMITIA (-propuesta de una- Metodología de Investigación Triangular para la elaboración de Indicadores de Accesibilidad).

La estrategia de investigación y de análisis combina métodos cuantitativos y cualitativos, interconectados mediante una secuencia de aplicación que ha de desarrollarse en tres fases:

1 La presente propuesta metodológica ha sido elaborada en el marco del desarrollo del Proyecto: RISE Women with disabilities In Social Engagement (RISEWISE), Comisión Europea, Programa H2020, (ref. H2020MSCA-RISE-2015: http://cordis.europa.eu/project/rcn/203392_en.html). Los autores colaboran en dicho proyecto a través del Grupo de Estudios Sociales sobre Discapacidad (GESODIS, grupo de investigación complutense 970607, http://www.um.es/discatif/gesodis.htm).

2 Desde que se promulgó la Convención Internacional de Derechos de las Personas con Discapacidad (ONU, 2006), se ha desarrollado un amplio conjunto de regulaciones de carácter normativo que promueven líneas de intervención para mejorar la situación de las personas con discapacidad. En lo que se refiere a la Unión Europea, destaca su plan estratégico de intervención en materia de discapacidad (Estrategia Europea sobre Discapacidad 2010-2020); en España, y al amparo de las directrices señaladas, se ha diseñado un plan estratégico de acción en materia de discapacidad: el Plan de Acción de la Estrategia Española sobre Discapacidad 20142020 (Ministerio de Sanidad, Servicios Sociales e Igualdad, 2014).

3 Cabe señalar, no obstante, algunas aportaciones recientes que apuntan en una dirección análoga a la del presente texto: Grasso et al (2017), Tenazas et al (2016), Alciva et al (2016), Romero y Castaño (2016I), Lizarazo et al (2015). 
- Fase 1: aplicación de cuestionarios exploratorios a personas con discapacidad y profesionales de la tecnología para determinar los perfiles más relevantes, en ambos casos, que puedan suministrar información acerca de las barreras de acceso a la tecnología con las que se encuentran las personas con discapacidad.

- Fase 2: investigación cualitativa mediante entrevistas en profundidad (EP), grupos de discusión (GD) y grupos triangulares (GT). Las entrevistas se aplicarán a las personas con discapacidad; los GD agruparán, por un lado, a las personas con discapacidad y a los profesionales de la tecnología, por otro, a las personas con discapacidad y sus familias; en tanto que los GT se realizarán con los profesionales.

- Fase 3: desarrollo de un conjunto de indicadores de accesibilidad, a partir de la información producida en las fases previas, que precisen las barreras tecnológicas en términos de innovación y de aceptación social de las tecnologías.

Como resultado, pues, lo que la presente propuesta metodológica trata de producir es un conjunto sistematizado y codificado de criterios de diseño tecnológico accesible para las personas con discapacidad.

Para ello, se van a tener en cuenta tecnologías de uso generalizado que requieren una adaptación específica para las personas con discapacidad; no se van a tomar en consideración aquellas herramientas e instrumentos tecnológicos diseñados exclusivamente para personas con discapacidad y que, por tanto, no son utilizados por el resto de personas (sillas de ruedas, aparatos de ayuda auditiva o visual, etc.). La razón es bastante obvia: estos últimos productos tecnológicos se desarrollan teniendo en cuenta a priori el grado de accesibilidad para sus usuarios/as, las personas con discapacidad, pues son las únicas destinatarias; las posibles barreras en cuanto a uso tienden a ser eliminadas y los tests de rendimiento son habituales. Al tomar en consideración tecnologías de uso generalizado, se puede establecer una comparación entre un uso "estándar" y el uso particular de las personas con discapacidad que, en general, será diferente al convencional, y que, en el proceso de adaptación, puede generar, además, sistemas de ayuda en forma de innovaciones sociales útiles para el resto de usuarios/as (Toboso, 2011) . $^{4}$

\section{Consistencia y coherencia metodológica de proMITIA}

En primer lugar, es necesario tener en cuenta el especial ámbito de investigación que constituye la discapacidad. Desde los años 80 se ha desarrollado una relativamente importante producción en el área de las Ciencias Sociales en relación con la discapacidad $^{5}$, determinando aspectos que venían siendo desatendidos hasta ese momento. Se conforma, a partir de estos trabajos, la dimensión social y contextual del fenómeno, abandonando las aproximaciones de carácter biomédico: la discapacidad

4 Son especialmente ilustrativos de este "efecto de extensión de uso" los sistemas de ayuda auditiva, diseñados en principio para personas con discapacidad visual y que a fecha actual son habituales en móviles, ordenadores, medios de transporte público, etc. y que son utilizados por todo el mundo.

5 Algunos de los trabajos más relevantes han sido: Finkelstein (1980), Topliss (1982), Oliver (1990), Bynce, Oliver y Barnes (1991), Morris (1991), Shakespeare (1993), Barton y Oliver (1997), Abberley (1998), Gleson (1999), Barnes (2007); entre otros. 
implica un colectivo y un contexto, dejando de ser una cuestión atribuible en exclusiva a la persona particular y a su presupuesto déficit ${ }^{6}$.

Es a partir de este espacio de investigación que se puede abordar la accesibilidad tecnológica de las personas con discapacidad, no como una cuestión que atañe a cada usuario/a en particular, sino al colectivo en su conjunto y a los modos en los que se desarrollan diseños y productos en el marco de tendencias de conjunto, que se producen en virtud de determinados contextos culturales, significados colectivos, prácticas profesionales, regulaciones normativas, protocolos de intervención, etc.

La complejidad de lo social, en general, y de la discapacidad, en particular, excede a la capacidad de análisis de estrategias exclusivamente métricas y prospectivas. Nuestro objetivo, distanciándonos de una perspectiva unilineal, es aproximarnos lo máximo posible a la "exactitud social" 7 . Y para ello, se desarrolla una estrategia "triangular" de investigación que pretende abarcar: 1) la experiencia de los agentes principales, 2) la experiencia de sus entornos afectivos y, 3) la experiencia de un entorno profesional que tiene especial incidencia en su vida.

El punto de partida es la consideración de que, de hecho, las personas con discapacidad se encuentran con barreras significativas en el uso de las tecnologías; esto es, barreras en cuanto a accesibilidad (lo que constituye un factor de exclusión social). Para detectar tales barreras, abordaremos la recogida de datos en dos dimensiones: una dimensión "extensiva" - desde el punto de vista de la temporalidad histórica: la experiencia acumulada en el uso tecnológico-, y otra "intensiva" -que abarca los distintos ámbitos institucionales que toman parte en la producción y acceso a la tecnología de las personas con discapacidad-. La metodología que se propone trata de elaborar una reconstrucción de esos dos tipos de realidades.

La propuesta y elección metodológica, por tanto, trata de articular dos planos: el del objeto y el del sujeto. A saber: 1) Garantizar la producción de discursos que nos permitan observar los principales elementos que están incidiendo en la existencia de barreras tecnológicas para las personas con discapacidad. 2) Brindar pautas y contenidos precisos de intervención para un adecuado desarrollo tecnológico orientado a usuarios/as con discapacidad (y, a su vez, trasladar dichas pautas a Administraciones Públicas, asociaciones, entidades colaboradoras y empresas que formen parte de los espacios de toma de decisiones en materia de accesibilidad tecnológica para las personas con discapacidad).

Es la conjugación de los planos objetivo y subjetivo la que permite establecer una adecuada combinación de las técnicas cualitativas y cuantitativas de proMITIA (véase el cuadro 1).

A partir de las premisas de esta línea de investigación, los integrantes del grupo GESODIS han producido un número importante de trabajos de investigación: Buchner et al (2015); Rodríguez Díaz y Cano Esteban (2015); Biewer et al (2015); Ferreira y Toboso (2014I; Toboso (2013); Toboso y Rogero (2012); Toboso et al (2012); Ferreira (2010a, 2010b); Rodríguez y Ferreira (2010); Huete, Sola, Lara y Díaz (2010); Ferreira y Ferrante (2010); Díaz (2009); Ferrante y Ferreira (2008); Ferreira (2008).

7 Esto es, el objetivo es alcanzar la máxima precisión explicativa e interpretativa a través del conjunto más amplio posible de referencias, buscando, no la omnicomprensividad, sino la acotación exhaustiva de lo investigado. Ello requiere la aplicación de métodos diferentes a los de naturaleza lógico-causal. Paradójicamente, en palabras de Jesús Ibáñez, el camino para alcanzar el máximo grado de exactitud social es la "anexactitud" metodológica; la anexactitud es la conexión entre la exactitud ideal y la inexactitud sensible, supone un paso al límite de lo inexacto (nos lleva, según la definición matemática estricta, de una función a su derivada, $\mathrm{f} \circledast \mathrm{f}$ ') «lo anexacto (...) es una variación problemática de las constancias teoremáticas» (Ibáñez, 1985: 40). 
Cuadro 1: Consistencia entre objetivos y técnicas de investigación

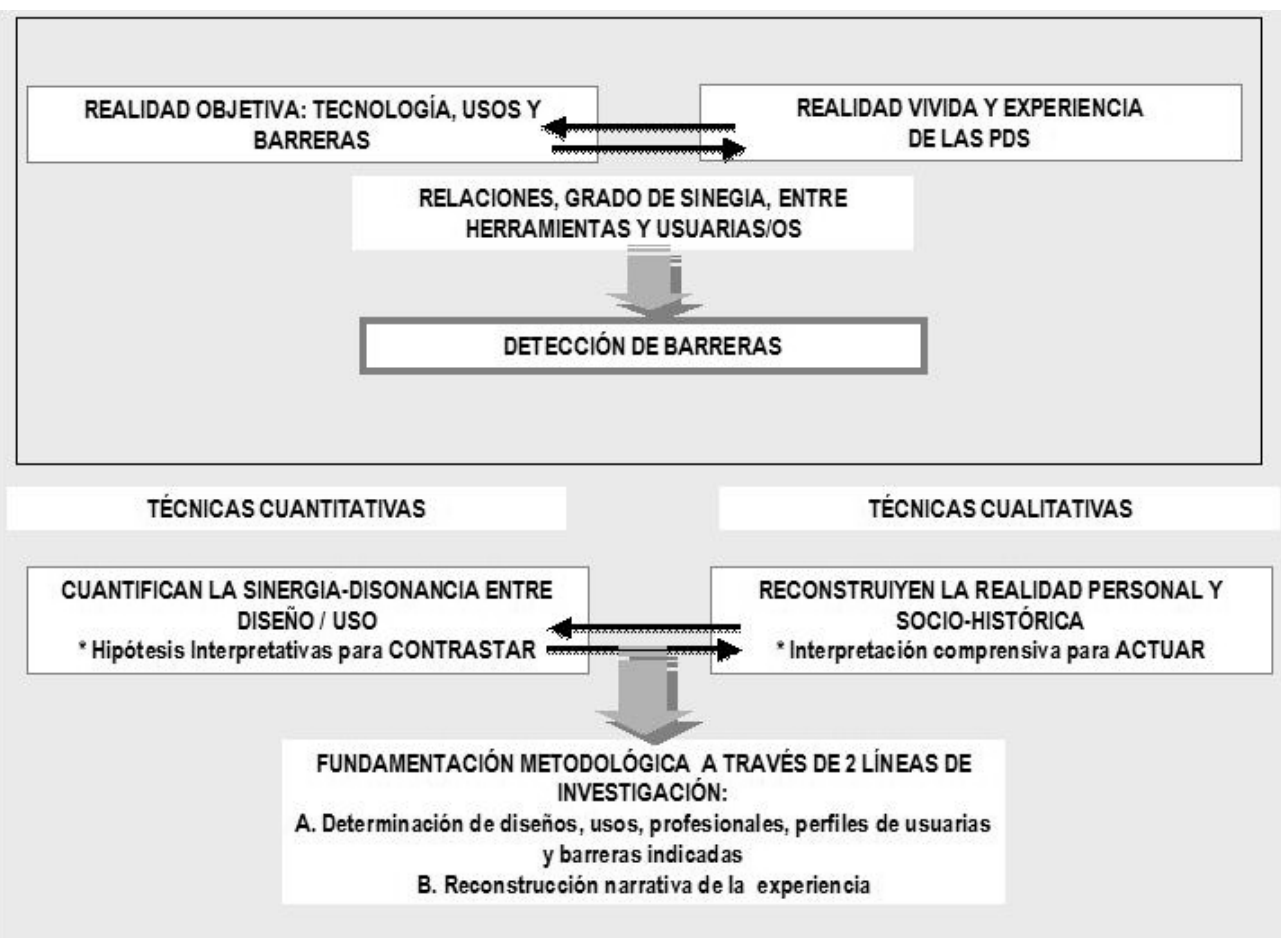

Son de especial relevancia, para obtener, a partir de las técnicas propuestas, una información relevante, los procesos de contactación y selección de las personas que tomarán parte en el estudio. Conviene, en este aspecto, anticipar un problema recurrente en los estudios sobre discapacidad, que se produce cuando la vía de acceso a potenciales sujetos de investigación se realiza exclusivamente a través de Asociaciones u otro tipo de organismos y entidades que suponen una vinculación formal de sus miembros: ello genera un sesgo sistemático en las muestras, pues la mayoría del colectivo de personas con discapacidad no forman parte de ese tipo de organizaciones. Es importante, pues, disponer de cauces de contactación alternativos (Toboso y Rogero, 2012).

A efectos del propio proceso de investigación en su desarrollo, la consistencia metodológica se apoya, fundamentalmente, en una adecuada articulación entre técnicas cualitativas y cuantitativas: la selección de la muestra de personas con discapacidad y profesionales de la tecnología a utilizar en la fase cualitativa ha de atender, no sólo a criterios distributivos de ponderación en función de sus perfiles, sino también a los intereses específicos de la investigación. En este caso, es recomendable asumir un sesgo positivo, privilegiando perfiles, en el caso de las personas con discapacidad, que muestren un alto grado de utilización de herramientas tecnológicas (serán ellas las que mayor información suministrarán sobre las barreras tecnológicas), aunque incluyendo también personas con un nivel menor de utilización de la tecnología, al efecto de poder ofrecer una visión comparativa entre ambos grupos (de aquí podría surgir, además, una cuestión adicional a considerar: ¿son las barreras una condición objetiva del uso tecnológico o bien están relacionadas con la percepción del usuario en función de la cantidad e intensidad de uso de la tecnología?). 
Por último, sólo se logrará obtener un adecuado grado de consistencia metodológica si la aplicación de las técnicas cualitativas se lleva a cabo con una bien delimitada secuenciación y articulación de las mismas. Las EP deben ser aplicadas en primer lugar para, a partir de la información recabada, determinar con mayor precisión la composición de los GD, así como las temáticas específicas, dentro de la propuesta genérica que ha de movilizar su dinámica discursiva (esto es, accesibilidad versus barreras), que habría que tomar en consideración. Sólo a partir de los datos obtenidos con ambas técnicas será posible diseñar el guión de las cuestiones que habrá que proponer a los profesionales en los GT. Esto determina una secuencia que, no obstante, en el proceso de investigación, ya con referencias concretas recopiladas, puede someterse a revisión (lo que se conoce como "vuelta atrás" o proceso de retroalimentación: cada una de las fases de la secuencia retroactúa sobre las demás en un proceso de carácter recursivo ${ }^{8}$ ).

En definitiva, la consistencia metodológica de proMITIA se apoya en 1) una selección de técnicas que se ajustan de manera adecuada a los objetivos de la investigación, y 2) un diseño, planificación, secuenciación y articulación de las mismas que permite recabar la información necesaria para el cumplimiento de dichos objetivos.

\section{Identificación de las barreras en el acceso de las personas con discapacidad al uso de tecnologías}

La investigación empírica basada en la metodología proMITIA identificará las barreras a las que se enfrentan en cuanto usuarias de herramientas tecnológicas las personas con discapacidad: para ello, en primer lugar y mediante los cuestionarios de la fase 1, se seleccionarán perfiles pre-definidos (en función de: edad, nivel socio-cultural y económico, nivel de estudios, situación laboral, "dependencia" de la tecnología., etc, en el caso de las personas con discapacidad; experiencia, productividad, ámbito de trabajo, difusión de productos y diseños, etc., en el caso de los profesionales de la tecnología) que más relevantes puedan ser para el diseño de una muestra representativa a la que aplicar las técnicas de investigación cualitativas.

Ulteriormente, una vez realizado el análisis de todo el material producido, se desarrollará un proceso de sistematización del mismo que permitirá elaborar los índices de accesibilidad tecnológica, unos indicadores que cuantificarán de manera precisa las dificultades concretas que se encuentran las personas con discapacidad en cuanto usuarios/as tecnológicos/as.

Sigamos, pues, la secuencia indicada en el apartado previo.

\subsection{Técnicas cuantitativas}

A partir de ellas, el objetivo es "cartografiar" (García Selgas, 2014; Gatti y Casado, 2001) el objeto de investigación: los sujetos implicados y las herramientas y pro-

8 Esta retroalimentación viene determinada por la lógica reflexiva de las prácticas sociales, tanto las cotidianas como aquellas que implica el desarrollo práctico de la investigación* 
fesionales involucrados. Para ello, la técnica más eficiente es el cuestionario, pues produce un espacio cerrado de ítems o categorías que pueden ser codificados y permiten la selección de las personas que habrán de intervenir en el estudio cualitativo (personas con discapacidad -y sus familias-; profesionales de la tecnología). De este modo, será necesaria la aplicación de dos cuestionarios.

Cuestionario 1 (personas con discapacidad)

El cuestionario considerará dos grupos diferenciados de variables, pues es necesario considerar: 1) el perfil sociológico genérico de la persona; 2) la especificidad de su discapacidad; y 3) su relación con las tecnologías. A tal efecto, las variables relevantes se agrupan en dos categorías distintas: 1) variables sociodemográficas y etiológicas; 2) Variables de incidencia tecnológica. Las mismas se desglosarían según se indica a continuación.

Variables socio-demográficas y etiológicas:

- Edad, nivel educativo, actividad profesional.

- Nivel socio-cultural y económico.

- Capital social (redes próximas y distantes).

- Tipo de discapacidad (según su clasificación clínica; y diferenciando si la misma es congénita o adquirida $-\mathrm{y}$, en el segundo caso, "desde cuándo"-).

- Familia: apoyo, indiferencia, rechazo.

Variables de incidencia tecnológica:

- Intensidad de uso (cuántas herramientas se utilizan; desde hace cuánto tiempo se vienen utilizando; cuánto uso temporal diario se les dedica).

- Tipo de uso dedicado a la tecnología: académico, profesional, de ocio.

- Facilidades de acceso a productos: particular, entidades de apoyo, administraciones públicas, etc.

- Elegibilidad de productos: oferta amplia / media / restringida.

- (Otras). 


\section{CUESTIONARIO 1}

Le agradecemos mucho su colaboración en este estudio. Asimismo, le queremos asegurarle que toda la información aportada es completamente confidencial y se ajusta a todos los protocolos actualmente vigentes al respecto.

A continuación le proponemos una serie de preguntas sencillas que ha de contestar según las indicaciones que se le señalan inmediatamente.

\section{UNAS PREGUNTAS SOBRE USTED (*)}

(Excepto en la primera, cuya casilla ha de rellenar, en el resto de las preguntas ha de seleccionar una, sólo una, de las opciones que se proponen)

1. ¿Sería tan amable de indicarnos su edad?.

2. Indique, por favor, su nivel de estudios:

2.1. Sin estudios

2.2. Primaria

2.3. Secundaria sin bachillerato / FP

2.4. Bachillerato

2.5. Grado Universitario

2.6. Máster o superior

2.7. No sabe /No contesta (NS / NC)

3. ¿Cuál es su situación laboral actualmente?

3.1. Estudiante.

3.2. Sin trabajo y sin pretensión de buscarlo.

3.3. Desempleado/a.

3.4. Trabajando.

3.5. NS / NC

En caso de estar trabajando, ¿qué tipo de actividad?:

3.6. Trabajo manual

3.7. Actividad Técnica/Administrativa

3.8. Actividad Ejecutiva intermedia .

3.9. Actividad Ejecutiva superior de Dirección.

3.10. NS / NC

4. ¿Qué tipo de lectura prefiere?:

4.1. Ninguna

4.2. Prensa, comics, etc.

4.3. Literatura de entretenimiento

4.4. Literatura clásica (narrativa)

4.5. Literatura clásica (poesía).

4.6. Literatura científica, ensayo, historia, etc.

4.7. NS / NC 
5. En relación con sus ingresos mensuales, ¿querría indicarnos su cuantía?

5.1. Menos de $500 €$

5.2. Entre $501 €$ y $1.000 €$

5.3. Entra $1.001 €$ y $2.00 €$

5.4. Entre $2.01 €$ y $3.500 €$

5.5. Entre $3.55 €$ y $5.000 €$

5.6. Más de $5.000 €$.

5.7. NS / NC

6. En cuanto a sus relaciones personales, señale cómo considera su situación:

6.1. Conozco a muy pocas personas, que son próximas..

6.2. Conozco a muy pocas personas y algunas están lejos

6.3. Conozco a pocas persona, tanto próximas como lejanas.

6.4. Conozco a muchas personas, todas próximas

6.5. Conozco a muchas personas, pero a distancia.

6.6. Conozco a muchas personas, próximas y en la distancia

6.7. NS / NC

7. ¿Nos podría indicar qué tipo de discapacidad tiene?

7.1. Física

7.2. Sensorial.

7.3. Mental

7.4. Intelectual.

7.5. Otra.

Por favor, especifique cuál:

7.6. NS / NC

8. Su discapacidad, ¿la tiene desde que nació o la adquirió más adelante?

8.1. La tengo desde el nacimiento

8.2. La adquirí de niño/a.

8.3. La adquirí en la juventud

8.4. La adquirí siendo ya adulto/a.

8.5. NS / NC

9. ¿Cuál diría usted que ha sido la actitud de su familia en relación con su discapacidad?

9.1. Mi familia se ha desentendido....

9.2. Mi familia se ha preocupado poco.

9.3. Mi familia se ha preocupado, aunque tampoco demasiado.

9.4. Mi familia se ha preocupado bastante

9.5. Se ha preocupado bastante y me han apoyado en todo

9.6. Mi familia, simplemente, se ha volcado conmigo

9.7. NS / NC 
AHORA, QUISIÉRAMOS HACERLE UNAS PREGUNTAS SOBRE SU USO DE LA TECNOLOGÍA $(* *)$

10. ¿Utiliza usted muchas herramientas e instrumentos tecnológicos? (móvil, ordenador, tablet, etc.; nos referimos a instrumentos que usa todo el mundo, no a los que usted tiene por su discapacidad y no utiliza la mayoría de la gente)

10.1. No utilizo ninguno

10.2. Utilizo sólo uno.

10.3. Utilizo varios (dos o tres)

10.4. Utilizo más de tres

10.5. Utilizo como media docena

10.6. Utilizo más de media docena

10.7. NX / NC

En caso de haber seleccionado la opción 1.1, no es necesario que responda a las siguientes cuestiones, que se refieren al uso de tecnologías. Le agradecemos mucho su colaboración y el tiempo dedicado en ella.

11. ¿Hace mucho tiempo que es usuario/a de tecnologías?

11.1. Las utilizo desde hace relativamente poco tiempo.

11.2. Las utilizo desde hace ya bastante tiempo.

11.3. Las vengo utilizando toda la vida

11.4. NS / NC

12. ¿Durante cuánto tiempo al día utiliza esas herramientas?

12.1. Menos de 1 hora

12.2. Entre 1 y 3 horas

12.3. Entre 3 y 5 horas

12.4. Entre 5 y 7 horas

12.5. Entre 7 y 10 horas

12.6. Más de 10 horas

12.7. NS / NC

13. ¿Con qué fin utiliza esas herramientas?

13.1. Las utilizo sobre todo para ocio.

13.2. Las utilizo sobre todo en los estudios.

13.3. Las utilizo sobre todo en el trabajo.

13.4. Las utilizo tanto en los estudios como para el ocio

13.5. Las utilizo tanto en el trabajo como para el ocio

13.6. Las utilizo en todo tipo de actividades

13.7. NS /NC.

14. ¿nos puede indicar cómo accede a esas herramientas?

14.1. Me las compro yo

14.2. Lo hago a través de una institución privada

14.3. Lo hago a través de una institución pública

14.4. Tengo varias vías, personales y privadas

14.5. Tengo varias vías, personales y públicas 
14.6. Tengo varias vías, personales, públicas y privadas

14.7. NS / NC

15. Díganos, por favor, el grado de acceso que tiene a esas herramientas y si satisfacen sus necesidades:

15.1. En general, no encuentro lo que necesito

15.2. Lo que necesito no es fácil de obtener

15.3. Lo que necesito se puede obtener pero resulta muy costoso

15.4. Lo que necesito es relativamente asequible y no muy caro

15.5. Lo que necesito es muy asequible en acceso y coste

15.6. Tengo todo lo que necesito siempre y muy barato.

15.7. NS / NC.

16. ¿Podría indicarnos su grado de satisfacción con los productos que utiliza?:

16.1. No estoy nada satisfecho/a

16.2. Estoy muy poco satisfecho/a

16.3 .Estoy moderadamente satisfecho/a.

16.4. Estoy bastante satisfecho/a

16.5. Estoy muy satisfecho/a

16.6. Estoy extraordinariamente satisfecho/a

16.7. NS / NC

Ya para finalizar, dos últimas cuestiones:

A. Indíquenos brevemente, por favor, qué barreras concretas ha encontrado en su acceso y uso de las tecnologías de las que dispone (escriba en la casilla; no hay límite prefijado de espacio):

B. Señale, si lo estima oportuno, alguna cuestión que no se haya contemplado en el cuestionario y usted considere de interés (escriba en la casilla; no hay límite prefijado de espacio):

End

$(*)$ Variables socio-demográficas y etiológicas.

$(* *)$ Variables de incidencia tecnológica.

En las preguntas que van a utilizarse para realizar una clasificación jerárquica de los/as entrevistados/as, la escala utilizada es 0-7.

(Ejemplo: P.2.; (2.1) Sin Estudios = 0... (2.6) Máster o superior =7)

El resto de las preguntas cualifican sin jerarquización (tipos discriminantes 0-5 ó 03).

(Ej. P.7: cualifican de 7.1 a 7.4, tipos 0 al 3; la opción 7.5 es un marginal, con nula o muy escasa probabilidad de presencia; los casos que la seleccionen, en caso de darse, deberán ser tratados de manera específica). 
Cuestionario 2 (profesionales de la tecnología)

Categorias:

- Experiencia (medida en tiempo de dedicación, con tres tramos: menos de 5 años, entre 5 y 10 años, más de 10 años; y en número de patentes).

- Especialidad: Tipo de ingeniería (u otra formación académica afín: física, matemáticas, etc.).

- Cooperación: relación con otros grupos de investigación/ trabajo a nivel nacional y/o internacional.

- Ámbito profesional de desempeño: público/ privado.

- Nivel de implantación de las tecnologías producidas (cantidad de usuarios, grado de internacionalización; outputs y "recursividad" -procesos de innovación y mejora-).

- Participación de usuarios/as en el diseño: sí/ no.

- Grado de satisfacción con los resultados obtenidos.

- Obstáculos detectados para el desarrollo de su actividad: infraestructuras, financiación, procedimientos administrativos.

- Aspectos relevantes relativos a la idiosincrasia específica a nivel nacional (grado de reconocimiento, visibilidad, cobertura legal-administrativa, recursos adicionales, ...)

- (Otras) 


\section{CUESTIONARIO 2:}

Le agradecemos mucho su colaboración en este estudio. Asimismo, le queremos asegurarle que toda la información aportada es completamente confidencial y se ajusta a todos los protocolos actualmente vigentes al respecto.

A continuación le proponemos una serie de preguntas sencillas que ha de contestar según las indicaciones que se le señalan inmediatamente.

\section{LE ROGAMOS QUE NOS RESPONDA A LAS SIGUIENTES CUESTIONES, SELEC-} CIONANDO UNA DE LAS OPCIONES QUE SE PROPONEN

1. ¿Nos puede indicar durante cuánto tiempo viene desarrollando su actividad actual?:

1.1. Menos de 5 años

1.2. Entre 5 y 10 años

1.3. Más de 10 años

1.4. No sabe /No contesta (NS / NC)

2. ¿En qué especialidad se ha formado?.

2.1. Especialidad (rellene, por favor, la casilla):

3. Su trabajo, ¿lo desarrolla en el sector público o en el privado?

3.1. En el sector público

3.2. En el sector privado

3.3. NS / NC

4. ¿Colabora con otros grupos de trabajo o investigación?

4.1. No, con ninguno.

4.2. Sí, con otros equipos nacionales del sector privado.....

4.3. Sí, con otros equipos nacionales del sector público

4.4. Con otros equipos nacionales, públicos y privados

4.5. Con equipos internacionales del sector privado

4.6. Con equipos internacionales del sector público

4.7. Con equipos internacionales, públicos y privados

4.8. Con equipos nacionales e internacionales privados

4.9. Con equipos nacionales e internacionales públicos.

4.10. Con equipos nacionales e internacionales, públicos y privados.

4.11. NS / NC

5. ¿Cuenta con alguna patente como resultado de su trabajo?

5.1. No, ninguna. 
5.2. Sí, una

5.3. Si, varias: menos de 5

5.4. Sí, varias: 5 ó más

5.5. NS / NC

6. ¿Sabe usted la cantidad de usuarios que han podido acceder a los resultados de su trabajo?

6.1. Denos, por favor, una estimación aproximada:

7. ¿Cuál es el alcance logrado por los productos que ha desarrollado?

7.1. El impacto ha sido mínimo

7.2. Ha tenido impacto sobre todo a nivel nacional

7.3. Ha tenido impacto sobre todo a nivel internacional

7.4. Su alcance ha sido tanto nacional como internacional

7.5. NS / NC

8. Sus diseños/ productos tecnológicos, ¿han generado outputs adicionales?

8.1. No, son productos, más o menos, "cerrados"

8.2. Sí, algunos

8.3. Sí, bastantes

8.4. NS / NC

9. Sus diseños/ productos tecnológicos, ¿se actualizan periódicamente?

9.1. No, nunca

9.2. Sí, cada cierto tiempo pero no muy a menudo

9.3. Sí, bastante a menudo

9.4. Permanentemente

9.5. NS / NC

10. ¿Ha encontrado obstáculos para el desarrollo de su trabajo?

10.1. No, ninguno

10.2. Sí, sobre todo por la disposición de infraestructuras

10.3. Sí, sobre todo en cuanto a financiación

10.4. Sí, sobre todo por cuestiones de carácter administrativo

10.5. Otros obstáculos

10.5.1 Por favor, indíquelos:

10.6. NS / NC 
11. ¿Han participado los/as usuarios/os a los que iban destinados los productos que ha desarrollado en su diseño?

11.1. No, no han participado.

11.2. Sí, han participado puntualmente

11.3. Sí, han participado en un grado importante

11.4. Sí, han participado a lo largo de todo el proceso

11.5. NS / NC

12. ¿Qué grado de satisfacción ha obtenido por la producción de sus diseños/ productos?

12.1. Ninguna satisfacción

12.2. Poca satisfacción

12.3. Una satisfacción moderada

12.4. Bastante satisfacción

12.5. Mucha satisfacción.

12.6. NS / NC

13. Por último, nos gustaría que nos indicase algún aspecto relevante que haya podido encontrar en cuestiones relativas a grado de reconocimiento, visibilidad, cobertura legal y administrativa, disposición de recursos adicionales, etc.

13.1. Por favor, señale lo que considere relevante (no hay restricción predeterminada en cuanto a extensión):

END

A efectos de codificación, todas las preguntas pertinentes se ponderan en una escala de 0 a 10 , aplicando a las respuestas con un coeficiente de homogenización $\boldsymbol{N}=(1 / \mathrm{n}) \times 10$.

La p. 2 es nominal y, dado el reducido número de especializaciones posibles, se espera un conjunto de categorías reducido; igualmente la p.6, que, a partir de las respuestas, generará las categorías "pocas, bastantes, muchas". La p.3, obviamente, es dicotómica.

La pregunta 11 es un discriminante primario, dado que indica el grado de participación de usuarios/as en el diseño y elaboración de las tecnologías que van a utilizar.

Puede consultarse una versión preliminar de dichos cuestionarios en el anexo que figura al final del texto (págs. 25-32) ${ }^{9}$. A partir de los mismos se pueden determinar categorías específicas, tanto de personas con discapacidad como de profesionales de la tecnología: para las personas con discapacidad, el criterio primario de distribución será su relación con la tecnología (variables de incidencia tecnológica) y a partir de él, se podrán determinar sub-categorías en función de la clasificación etiológica y

9 Teniendo en cuenta que proMITIA se diseña como instrumento metodológico de un proyecto de investigación comparativo de carácter internacional, se han omitido en los cuestionarios los aspectos que remiten a las particularidades nacionales en lo relativo a la actividad de los profesionales de la tecnología: en cada caso, habrá que ajustar los cuestionarios a las mismas. 
socio-demográfica. En el caso de los profesionales de la tecnología, el criterio primario será la participación de los/as usuarios/as en el diseño y desarrollo de los productos tecnológicos; a partir de él, las sub-categorías se establecerán bajo una gradación en cuanto a "importancia y volumen" del trabajo realizado (atendiendo al grado de experiencia, al nivel de cooperación con otros equipos de trabajo y al impacto logrado por las tecnologías producidas), distinguiendo como categorías diferentes a quienes desarrollan su trabajo en el sector público y los que lo hacen en el sector privado (distinción que, muy probablemente, mostrará una correlación significativa en cuanto a la percepción de obstáculos para el adecuado desarrollo de su trabajo).

\subsection{Técnicas cualitativas}

Las técnicas cualitativas se muestran como un potente dispositivo de investigación que permite la incorporación de dos dimensiones sociales básicas y su articulación recíproca; a saber: la dimensión estructural con y la biográfico-individual.

En términos de planificación metodológica, se propone la una convergencia estratégica y planificada de diferentes técnicas de investigación:

1. Entrevistas abiertas semi-pautadas en profundidad.

2. Grupos de discusión o reuniones de grupo canónicas.

3. Grupos triangulares o mini-grupos centrados.

En el cuadro 2 presentamos la articulación gráfica de la planificación metodológica, con los niveles técnicos, y epistemológicos, en diversos planos de significado.

Cuadro 2: Articulación de las técnicas cualitativas y sus niveles de significado

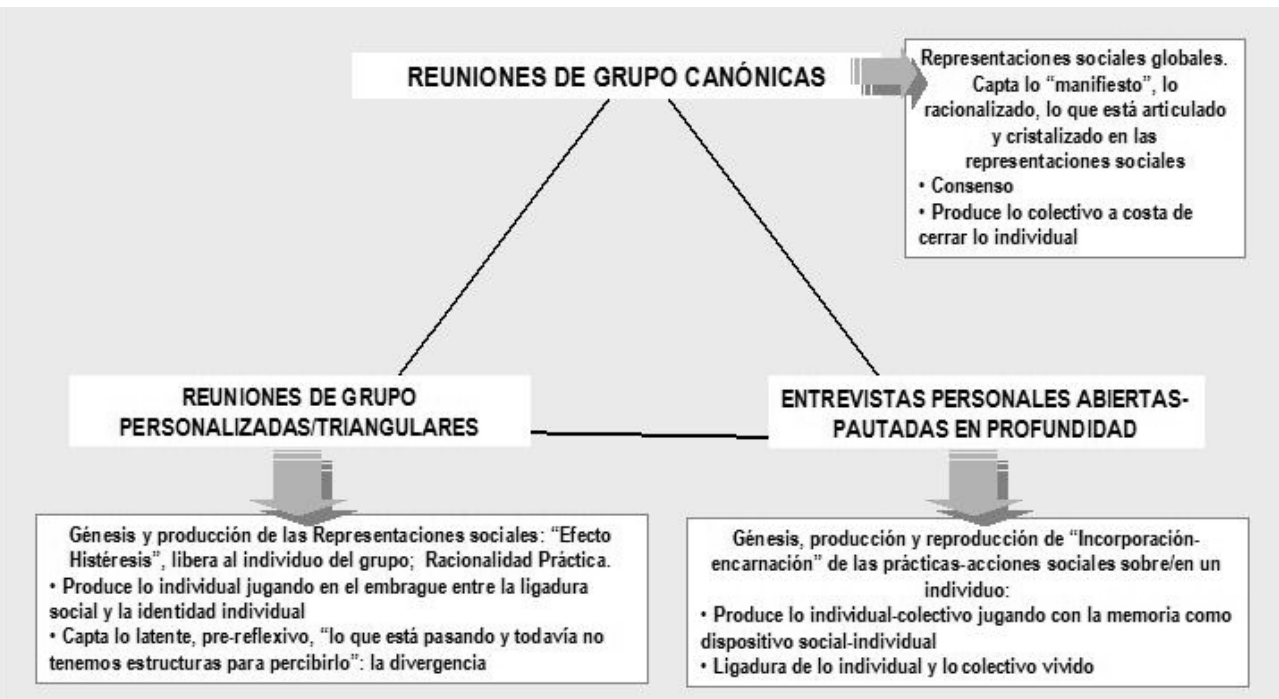


El dispositivo específico de investigación permite aunar las dimensiones individuales-biográficas (a través de la entrevistas abiertas) y las dimensiones sociales colectivas (a través de los Grupos de Discusión Canónicos) y, finalmente, las dimensiones de tensión entre las representaciones sociales colectivas y la perspectiva del actor individual (a través de Grupos Triangulares o centralizados). En el cuadro 3 se muestra dicha conjunción de manera gráfica.

Cuadro 3: Articulación de los niveles colectivo y biográfico-personal y las tensiones entre ambos

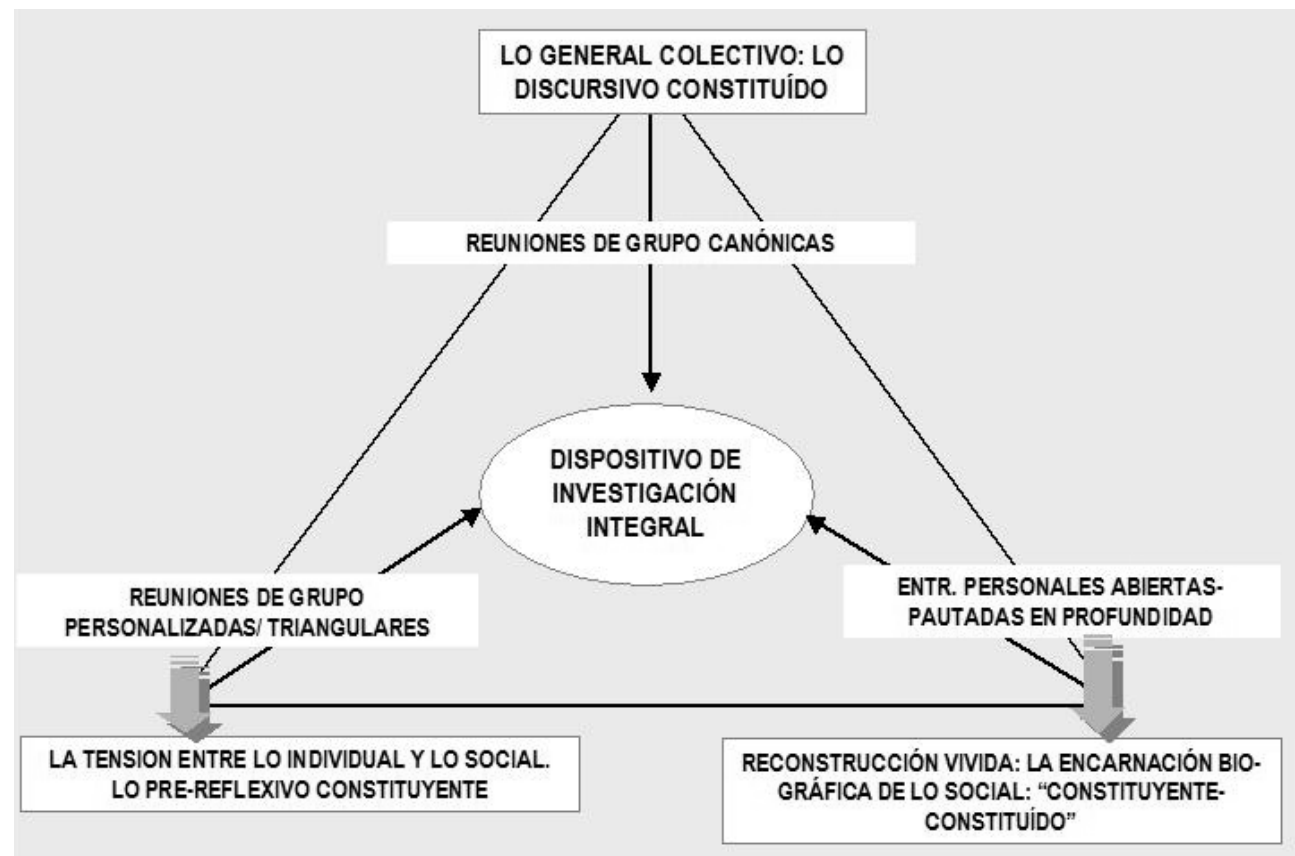

Esta conjunción, orientativamente, la podemos traducir en la producción de diferentes narrativas que nos garantizan, en la medida de lo posible, la reconstrucción lo más hologramática y global de la configuración social de las personas con discapacidad en su experiencia como usuarias de tecnología. En el cuadro 4 se señalan esos distintos niveles narrativos y vivenciales que recogerá el dispositivo de investigación, poniendo de nuevo el acento en la, imprescindible, consistencia metodológica. 
Cuadro 4: Niveles y narrativos vivenciales recogidos por las técnicas de investigación cualitativas de proMITIA

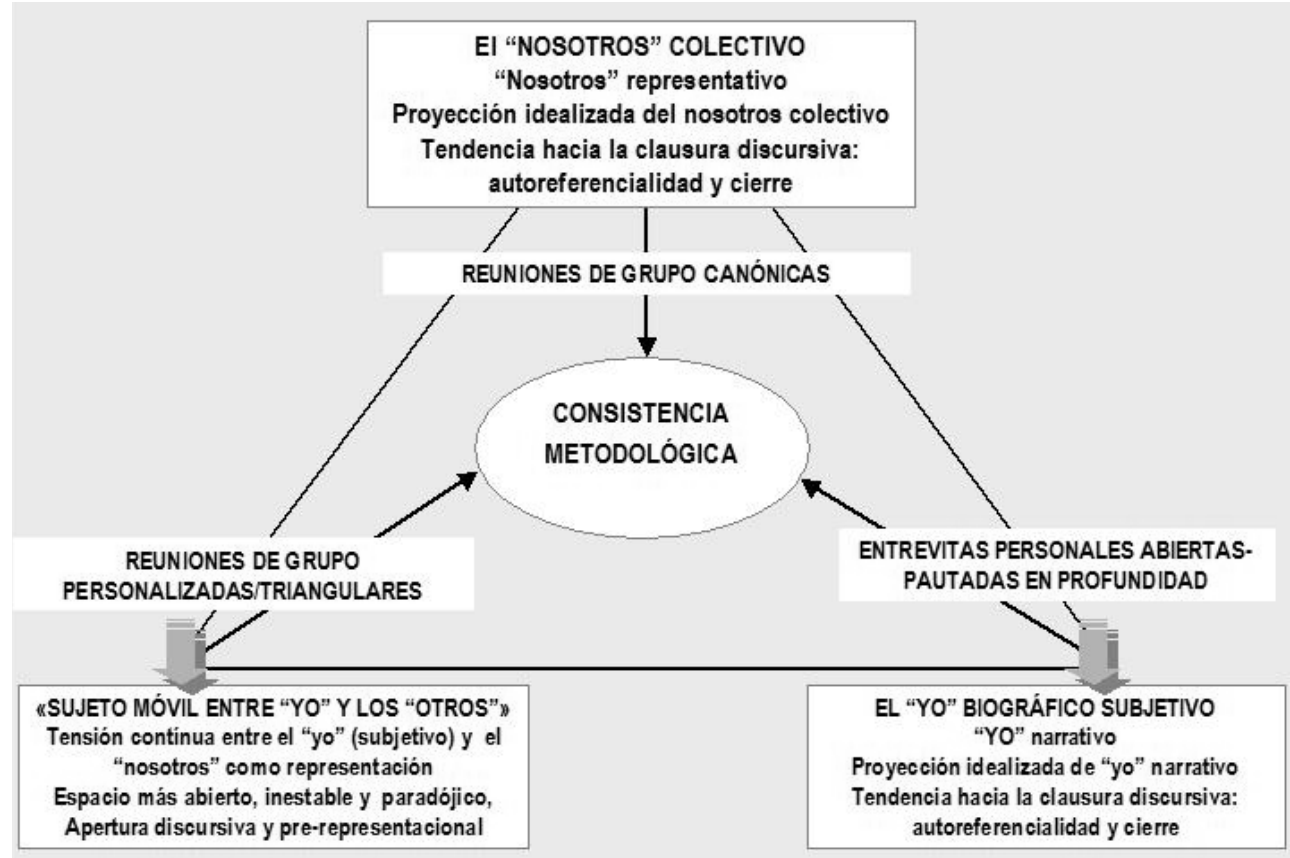

Por último, la distribución de la muestra recabada a partir de los cuestionarios, y de acuerdo con las diferentes técnicas de investigación cualitativas, se determinará tomando en consideración las siguientes variables:

- Personas con discapacidad: Nivel educativo; ámbito geográfico de pertenencia $^{10}$; "clase social" según capital económico y cultural (alta, intermedia, baja discapacidad.

- Profesionales de la tecnología. Experiencia; desarrollo de la actividad en el sector público en el privado; grado de contacto con las personas con discapacidad en cuanto usuarias (estimable a partir de la participación de las mismas en los procesos de diseño tecnológico).

10 En consonancia con la clasificación utilizada en el proyecto Quali-TYDES, la categorización en el caso del ámbito geográfico de pertenencia será "central” o "Periférico"; un ámbito central se caracteriza por una amplia disponibilidad de recursos para los habitantes de carácter económico y cultural, así como un una importante influencia en la toma de decisiones políticas (implica, necesariamente, un hábitat urbano, aunque no se considera como tal, ni en lo relativo a su tamaño demográfico, sino en cuanto al volumen de capitales económico y cultural que ofrece); un ámbito periférico, por el contrario, ofrece pocos recursos culturales y económicos y tiene escasa incidencia en los procesos de decisión política (puede remitir tanto a un entorno rural como a uno urbano). Esta tipificación está directamente relacionada con la clasificación de las personas con discapacidad según su posición social objetiva (los ámbitos periféricos aglutinan muchas posiciones sociales bajas; los ámbitos centrales acaparan la mayoría de las posiciones sociales altas e intermedias). Se constata, a partir de las entrevistas realizadas para Quali-TYDES, la pertinencia de la distinción (véase: Rodríguez y Cano, 2015: 176-230). 


\section{Entrevistas en profundidad -}

La entrevista personal, como su nombre indica, es la realización "cara a cara" de una "conversación" personal entre el entrevistador y el entrevistado en la que se trata de generar un "proceso comunicativo" en el que el entrevistado-informante exprese de la forma más libre, distendida y espontánea posible el conjunto de vivencias y de su puntos de vista personales sobre el tema investigado. De este modo, la información está anudada en la biografía del interlocutor, entendiendo por biografía "el conjunto de las representaciones asociadas a los acontecimientos vividos por el entrevistado.". El yo de la entrevista -por tanto-, es un yo "que poco tiene que ver con el yo como realidad objetiva, individualista y racionalizado... sino un yo narrativo, un "yo" que cuenta historias en las que se hace posible un bosquejo del yo como parte de la historia (Alonso, 1995)".

La técnica de la entrevista abierta, se muestran como una herramienta extraordinariamente interesante para obtener información de carácter pragmático, es decir, "de cómo los sujetos diversos actúan y reconstruyen el sistema de representaciones sociales en sus prácticas individuales (Alonso, 1995)".

\section{Grupos de discusión -}

Los grupos de discusión ( 7 a 8 personas que no se conocen y se sientan a discutir un tema propuesto por un/a coordinador/a) en la medida que producen una discusión bastante espontánea, franca y abierta, posibilitan el estudio de los discursos sociales, de los argumentos, pros y contras de los mismos, etc...; al mismo tiempo, el propio calor de la conversación obliga a que aparezcan los perfiles y matices más importantes del tema que se está investigando. Emergen las articulaciones de los discursos y las diferenciaciones sociales entre los mismos, etc.: emerge el "nosotros" colectivoafectivo como espacio intermedio entre la sociedad abierta y el yo-individual.

\section{Grupos triangulares o mini-grupos ${ }^{11}-$}

Si el anterior tipo de reuniones son instrumentos técnicos de trabajo muy apropiados para abordar todo lo referente a las percepciones globales, a los sistemas de imágenes, a las diferencias perceptivas generales, etc., la propia dinámica hace que los discursos se desplieguen en el terreno de "lo general", terreno en el que se inscriben dichos campos de imágenes.

Por el contrario, los grupos triangulares de tres personas y una mayor duración, se manifiestan como una técnica pertinente para avanzar lo concreto y específico: produce discursos individuales que se contrastan y someten a debate. Ponen en evidencia de las diferencias sobre lo concreto y son poco dados a la dispersión, facilitando una mayor concentración en el material expuesto.

Estimamos que esta técnica de investigación cualitativa, realizada en el colectivo de los profesionales del desarrollo y diseño de herramientas tecnológicas orien-

11 El desarrollo de esta práctica cualitativa puede leerse (Conde, 1993). 
tadas a las personas con discapacidad, nos va a permitir una mediación eficaz y comprensiva entre los polos centrales de la enunciación y la recepción, en este caso, relativos a la tecnología y la relación con la misma de las personas con discapacidad. Esta mediación, permitirá obtener una orientación precisa para la generación medidas eficaces de supresión de barreras de accesibilidad.

Resta, a partir de la determinación de tales medidas, una tarea ulterior de sistematización del material producido que sirva como referencia codificada para la efectiva puesta en marcha de las mismas, con un grado de transferencia razonable. Para ello, se elaborará un conjunto de indicadores de accesibilidad.

\section{Elaboración de los indicadores de accesibilidad y barreras}

Hemos de situar el modelo de diseño de indicadores que se propone en el marco conceptual a partir del cual se elabora. El punto de partida es la consideración de la aceptación social de innovaciones, que alude al hecho de que una innovación propuesta no se hace de hecho efectiva sin que se dé una aceptación de la misma por parte de un colectivo determinado.

El estudio de la aceptación social de innovaciones analiza realidades de adopción diferenciadas, usos locales situados y concretados en contextos y grupos particulares. Es importante, por ello, atender a los imaginarios y discursos sociales, tanto favorables como desfavorables, hacia las innovaciones, en los que se recogen conjuntos de valores, representaciones y prácticas a través de los cuales distintos agentes las significan de manera distinta.

La aceptación de una novedad, o innovación propuesta, que denotamos $X$, por parte de una comunidad $\mathrm{C}$ se ve mediada y significada por formas de socialización de aquélla novedad en ciertos espacios que denominamos entornos prácticos de la comunidad, que denotamos por E. Estos entornos prácticos son los espacios de presencia y participación de la comunidad. Se trata de entornos en los que circulan representaciones y prácticas sociales compartidas, junto con valores relevantes para la comunidad. Vamos a interpretar los entornos prácticos como espacios de funcionamientos, en el sentido de Amartya Sen (1985, 1993), siendo los funcionamientos prácticas socialmente valoradas.

Dado un entorno práctico, este ofrecerá un conjunto de funcionamientos posibles en su relación con la comunidad presente en él. Dentro del conjunto de funcionamientos considerados valiosos por la comunidad en ese entorno, los habrá cuyo logro se vea satisfecho en diferente grado. Atenderemos, en calidad de indicadores, tanto al "grado de satisfacción", como al "grado de importancia" otorgado por la comunidad a $\operatorname{los} n$ funcionamientos particulares $f_{j}$ en el entorno práctico dado (véase la Tabla I). Diremos que el funcionamiento particular $f_{j}$ se ve afectado por una barrera (funcional o de funcionamiento) en el entorno dado si su importancia es considerada alta y su satisfacción baja. Análogamente, el funcionamiento $f_{j}$ implica un facilitador si su importancia es considerada alta y su satisfacción también. Tales facilitadores y barreras no son inherentes al entorno ni a la comunidad, sino que se definen como tales en la relación práctica de funcionamiento entre ambos. 
Tabla 1: Funcionamientos de la comunidad $\mathrm{C}$ en el entorno práctico E, según grado de importancia y satisfacción

\begin{tabular}{|c|c|c|c|c|c|}
\cline { 2 - 6 } \multicolumn{1}{c|}{} & \multicolumn{5}{c|}{ Entorno E } \\
\hline Funcionamientos $\rightarrow$ & $f_{1}$ & $f_{2}$ & $f_{3}$ & $\ldots$ & $f_{n}$ \\
\hline Grado de importancia & $i_{1}$ & $i_{2}$ & $i_{3}$ & $\ldots$ & $i_{n}$ \\
\hline Grado de satisfacción & $s_{1}$ & $s_{2}$ & $s_{3}$ & $\ldots$ & $s_{n}$ \\
\hline
\end{tabular}

Acotación de valores para

los grados de importancia y de satisfacción:

$$
0 \leq i_{j}, s_{j} \leq 1
$$

En nuestro caso, los funcionamientos remiten a usos tecnológicos por parte de las personas con discapacidad dentro de su(s) comunidad(es) de pertenencia, en tanto que los entornos prácticos constituyen sus espacios habituales de funcionamiento (hogar, escuela, trabajo, etc.); la supresión de barreras de acceso a la tecnología se relacionará con la adopción de innovaciones (intentos de solución) tendentes a mejorar la accesibilidad.

Cuando en el entorno o en la comunidad se introduce una novedad o elemento innovador $X$, orientado a incrementar el grado de satisfacción de los funcionamientos afectados por barreras, habrá que tener en cuenta la influencia del nuevo elemento $X$ sobre el valor del grado de satisfacción de tales funcionamientos, a los que se aplica el elemento innovador.

Hay que tener en cuenta que el elemento $X$ se desarrolla y se introduce en el entorno o en la comunidad a partir de un determinado contexto social, económico, productivo, cultural, etc., que implicará múltiples valores. Así, además del conjunto de valores "instrumentales" de $X$ habrá que atender también a su participación en un marco de valores contextuales. En el estudio de la aceptación de $X$ por la comunidad vamos a considerar la falta de satisfacción de valores importantes para la comunidad como barreras axiológicas para dicha aceptación (por ejemplo, su disponibilidad, precio, apariencia, marca, necesidad, sencillez, accesibilidad, usabilidad, utilidad, seguridad, fiabilidad, comodidad, eficacia, calidad, etc.).

Sobre el conjunto particular de los valores evaluados como importantes, tanto instrumentales como contextuales, el elemento $X$ será evaluado igualmente por la comunidad de modo más o menos satisfactorio. Este proceso de evaluación revelará la presencia de barreras y facilitadores axiológicos en la relación entre la comunidad y el elemento $X$ dentro del entorno particular de que se trate. En la tabla 2 se expresa esta dimensión valorativa, axiológica, de la innovación introducida. 
Tabla 2: Dimensión axiológica de la innovación $\left(X \rightarrow X^{*}\right)$

\begin{tabular}{|c|c|c|c|c|c|}
\cline { 2 - 6 } \multicolumn{1}{c|}{} & \multicolumn{5}{|c|}{ Elemento $X^{*}$} \\
\hline Valores de $X^{*} \rightarrow$ & $V_{1}$ & $V_{2}$ & $V_{3}$ & $\cdots$ & $V_{m}$ \\
\hline Grado de importancia & $I_{1}$ & $I_{2}$ & $I_{3}$ & $\ldots$ & $I_{m}$ \\
\hline Grado de satisfacción & $S_{I}$ & $S_{2}$ & $S_{3}$ & $\ldots$ & $S_{m}$ \\
\hline
\end{tabular}

Acotación de valores para

los grados de importancia y de satisfacción:

$$
0 \leq I_{j}, S_{j} \leq 1
$$

A partir de aquí, podemos definir los indicadores de accesibilidad tecnológica para las personas con discapacidad, considerando que la aceptación del elemento $X$ por la comunidad implica dos dimensiones distintas: una axiológica y una funcional La dimensión axiológica de la aceptación social viene expresada por las variables $V_{k}$ consideradas en la tabla II, que constituyen el conjunto de valores instrumentales y contextuales del elemento $X$ en su relación con la comunidad. Las variables $V_{k}$ vienen definidas por dos indicadores: su grado de importancia $I_{k}$ y su grado de satisfacción $S_{k}$. La dimensión funcional se expresa mediante los indicadores análogos, referidos al grado de importancia y al grado de satisfacción de los funcionamientos tomados en consideración en la tabla 1.

A partir de la consideración del conjunto de funcionamientos implicados en el uso de una determinada tecnología, será posible, a su vez, elaborar un conjunto de indicadores para la misma que revelarán los factores que inciden en la generación de barreras de acceso a la tecnología que se encuentran las personas con discapacidad; ampliando el número de herramientas tecnológicas que se tomen en consideración, se ampliará, a su vez, la cantidad de indicadores disponibles para determinar en su conjunto la problemática de la accesibilidad de las personas con discapacidad a la tecnología.

Una medida de corrección en el diseño de la tecnología o en lo relativo a su uso puede suprimir las barreras de accesibilidad a la misma por parte de las personas con discapacidad. Si esto se da, se habrá logrado, efectivamente, la aceptación social de la tecnología utilizada. Reiteremos que para que esto pueda darse es necesaria una interacción entre la comunidad, sus entornos prácticos, los procedimientos funcionales y los esquemas de valoración aplicados (ninguna modificación puntual podrá ser eficiente).

El grado en el que las personas con discapacidad, dentro de una comunidad, logran una mayor o menor accesibilidad a la tecnología, remite a las modificaciones e innovaciones que la comunidad pueda introducir, que ya no pueden ser consideradas como meras operaciones técnicas o expertas, ya que comportan una conjunción de lo colectivo y contextual, lo estrictamente funcional o instrumental, lo valorativo, así como la capacidad práctica de los agentes para introducir también modificaciones en función de su mayor o menor grado de aceptación social. 


\section{Aplicación de la metodología proMITIA (fase preliminar)}

En el marco del proyecto RISEWISE mencionado al inicio del texto, este diseño metodológico ya está siendo implementado, tratando de abarcar, no sólo la accesibilidad tecnológica sino el acceso "global" de las mujeres con discapacidad en la Unión Europea a una inclusión social sin barreras.

Hemos omitido, a efectos de la claridad expositiva, el aparato matemático implicado en la elaboración de los indicadores de accesibilidad y de barreras. Ese diseño matemático puede consultarse en http://www.asesdis.es/vdocs/Ind_proM.pdf. Sobre la base del mismo, ya está en marcha el diseño de una herramienta para la recopilación de información empírica: un cuestionario on-line que será aplicado en 7 países como paso preliminar para la obtención de información cuantitativa sobre las dificultades para la integración social de las mujeres con discapacidad.

El recurso, provisionalmente de acceso restringido, puesto que está en proceso de validación (con dos tests de viabilidad en curso), se encuentra alojado en la dirección web que se indica a continuación (página siguiente), junto con una muestra gráfica de diversas "etapas" del cuestionario a cumplimentar por las mujeres con discapacidad que sean seleccionadas para el estudio. Se correspondería con el cuestionario 1 propuesto para la aplicación de la metodología proMITIA, ampliando la accesibilidad tecnológica en términos de "participación social": se mantiene la estructura de las variables socio-demográficas y en lo relativo a accesibilidad se contemplan cinco entornos (hogar; educación; trabajo, ámbito sanitario; ocio y entretenimiento), señalando diversos funcionamientos específicos en cada uno de ellos que deben ser evaluados en cuanto a su grado de importancia y de realización en una escala $0-5^{12}$. Una vez detectados los funcionamientos "problemáticos" (barreras) se determinarán posibles "facilitadores" y se evaluará el impacto efectivo de su introducción en cada entorno, midiéndolo a partir del cuestionario y su escala.

Con los datos obtenidos en una primera fase de aplicación (2017-2018), la expectativa es, sumando los resultados generados en todos los países y el análisis de datos, redefinir el diseño de la herramienta, en términos de la propia accesibilidad de la misma para su aplicación y de la determinación cuantitativa de los indicadores, para establecer de manera permanente la aplicación para su utilización en diversas investigaciones actualmente en fase de proyecto., recuperando la pretensión originaria de proMITIA en cuanto al estudio específico de la accesibilidad tecnológica, considerando la misma encuadrable de manera diferencial en los distintos entornos de funcionamiento.

12 Dicha escala obedece a dos criterios: en primer lugar, evitar la posibilidad de generar una "respuesta neutra", evitando una cuantificación con un término medio ( $\mathrm{n}$ respuestas negativas, $\mathrm{n}$ respuestas positivas y una posible respueta intermedia); en segundo lugar, a la hora de traducir la escala generada por el cuestionario a un indicador de valor 0 a 1, evitar la "pérdida" de restos decimales. 
Encuesta on-line RISEWISE V.0 (en fase de desarrollo) Alojamiento provisional: http://encuestas.trs.ucm.es/index.php/347343
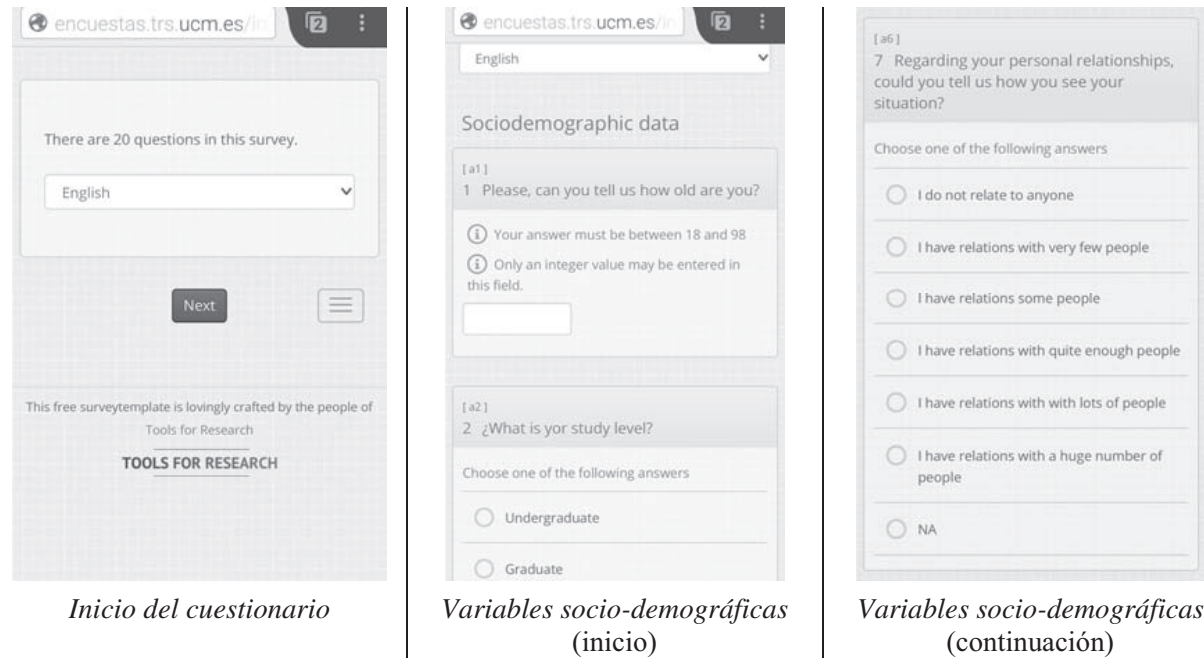

Variables socio-demográficas (continuación)
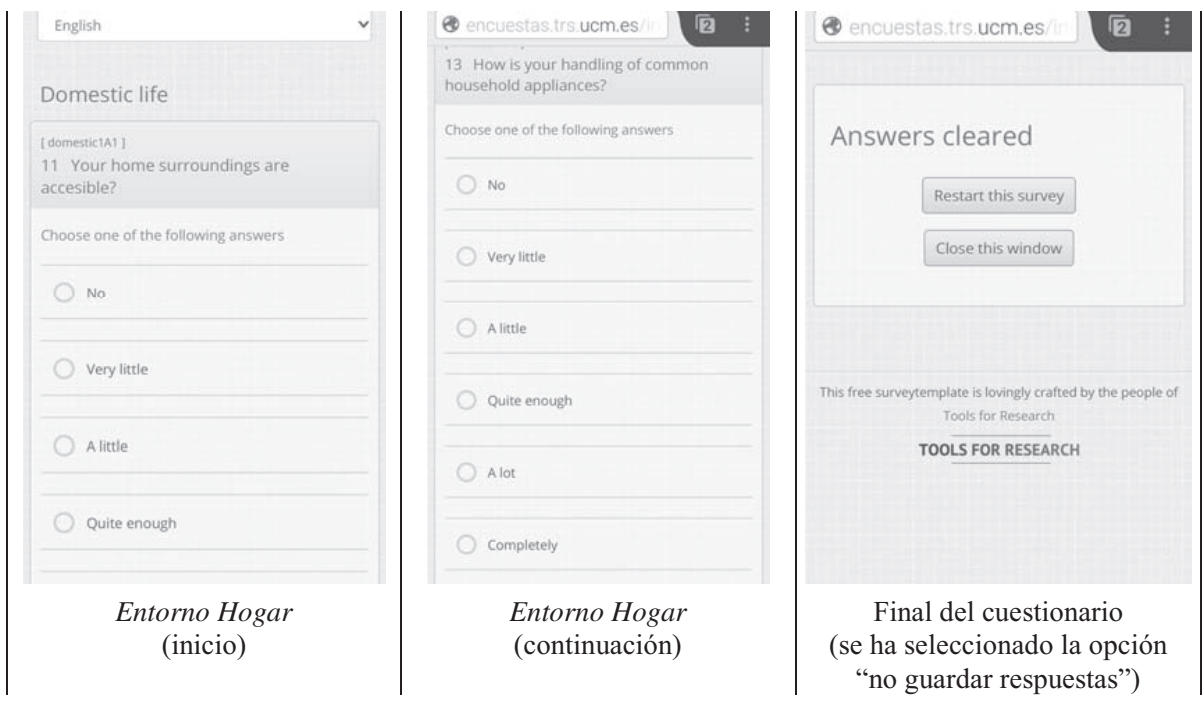


\section{Conclusiones}

Mediante la metodología proMITIA es posible abordar la problemática de la accesibilidad tecnológica para las personas con discapacidad mediante una aproximación que sitúa el foco de atención en la experiencia práctica de dichas personas, distanciándose de planteamientos unilineales determinados fundamentalmente por la perspectiva de los expertos en tecnologías, pero tomándola en consideración, no como la única, pero sí como una de las vías para poder determinar dónde se sitúa el problema y cuáles son sus posibles soluciones (más que el propio conocimiento experto, lo que se introduce en la investigación es la experiencia práctica desarrollada a partir del mismo).

La "potencia" del instrumento se deriva de la utilización de diversas técnicas de investigación que se combinan en un dispositivo de investigación integral en el que la secuencia de aplicación de las mismas y su interconexión están perfectamente delimitadas. Además, como resultado de dicha integración, se puede proponer como producto final un conjunto sistemático de cuantificadores. No es necesario señalar que la información recabada mediante tales técnicas puede ser a su vez de enorme utilidad para otros intereses de investigación, al tiempo que proMITIA puede ser empleada para abordar muchas otras problemáticas ${ }^{13}$.

Esta metodología permite el acceso a la voz en primera persona de las personas con discapacidad, algo que no se da en la gran mayoría de los ámbitos de investigación cuyo objeto es la discapacidad (más allá de la específica cuestión que aquí nos interesa, la accesibilidad tecnológica). Esta es una reclamación que se viene dando desde los inicios de los Disability Studies en el mundo anglosajón (Oliver, 1998, 2002).

Otra de las ventajas del instrumento de investigación presentado es la posibilidad que ofrece de poder ser aplicado, no en su conjunto, sino de manera parcial, sirviéndose de alguno de los bloques metodológicos que lo integran. A partir de los cuestionarios únicamente es posible extraer información cualitativa relevante cara a un mayor y mejor conocimiento de la realidad de las personas con discapacidad; la parte cualitativa puede llevarse a cabo mediante la selección de una muestra obtenida a partir de fuentes secundarias y de otros trabajos previos; a su vez, cada una de las técnicas de la misma pueden ser aplicadas de manera independiente; por último, de igual manera, para la elaboración de los índices de calidad puede realizarse utilizando información ya recopilada. Cada una de esas aplicaciones parciales recogerá tan sólo alguno de los aspectos que componen la visión integral que se propone alcanzar, pero pueden generar resultados de investigación de gran relevancia.

En definitiva, proMITIA se diseña como un instrumento de investigación que pretende abarcar el mayor número de variables relevantes para el estudio de la accesibilidad tecnológica de las personas con discapacidad, y, a la par, como una herramienta polivalente susceptible de ser aplicada en otros escenarios distintos. La codificación final resultante, en forma de unos indicadores de accesibilidad que parten para su elaboración de la consideración de la aceptación social de las innovaciones, situando las mismas en su contexto social de producción y aplicación, al sistematizar la información en términos de comunidades de uso y sus entornos prácticos, de los funcionamientos y las valoraciones generados y del grado de importancia y satisfacción que dichas novedades alcanzan en esos sus contextos de aplicación, ofrece lo que podríamos denominar como una cuantificación encarnada del fenómeno: es la experiencia práctica, las apreciaciones y valoraciones de los agentes formuladas 
en primera persona (haciendo explícitos los marcos de significación en los cuales producen sus asignaciones de sentido), la constatación de un proceso dinámico modelado por condicionantes tanto internos como externos, lo que permite elaborar un conjunto sistemático de cuantificadores que "retratan" la problemática que gira en torno a la accesibilidad tecnológica de las personas con discapacidad. Dicha sistematización permitirá una adecuada orientación en los procesos de diseño tecnológico, a la par que puede servir de guía para el desarrollo de políticas públicas más acordes con las auténticas necesidades de las personas con discapacidad.

\section{Bibliografía}

Abberley, P. (1987): «The concept of opression and the development of a social theory of disability», en Disability, Handicap \& Society, vol. 2, n 1, pp. 5-19.

Abberley, P. (1998): «Trabajo, utopía e insuficiencia», en Discapacidad y sociedad, Barton, L. (comp.), Madrid, ed. Morata.

Abberley, P. (2008): «El concepto de opresión y el desarrollo de una teoría social de la discapacidad», en Barton, L. (comp.). Superar las barreras de la discapacidad. Morata, Madrid.

Alcívar, G. A.; Bravo, S. D.; Villafuerte, J. S. (2016). "Estimulación del remanente visual de niños de baja visión, con un programa informático y su efecto en el rendimiento académico", en Píxel-Bit: Revista de medios y educación, n. 48; pp. $115-134$.

Alonso, L. E. (1995). "Sujeto y discurso: el lugar de la entrevista abierta en las prácticas de la investigación cualitativa", en Delgado, J. M. y Gutiérrez, J. Métodos y técnicas cualitativas de investigación en ciencias sociales. Síntesis, Madrid, pp. 225-240.

Barnes, C. (1991). "Discrimination: Disabled people and the media", en Contact $\mathrm{n}^{\circ}$ 70 , pp. $45-48$.

Barnes, C. (2007). "Disability activism and the price of success: A british experience", en Intersticios: Revista Sociológica De Pensamiento Crítico, vol. 1, n. 2, pp. 15-29. Disponible en: http://www.intersticios.es/article/view/697/855

Barton, L. y Oliver, M. (1997). Disability studies, past, present and future. The Disability Press, Leeds.

Biewer, G.; Buchner, T.; Shevlin, M.; Smyth, F.; Šiška, J.; Káňová, S.; Ferreira, M. A. V.; Toboso Martin, M.; Rodríguez Díaz, S. (2015): «Pathways to inclusion in european higher education systems», en Alter - European Journal of Disability Research, Revue Européenne De Recherche Sur Le Handicap, vol. 9, n. 4, pp. 278-289. Disponible en: http://www.sciencedirect.com/science/article/pii/ S1875067215000206

Buchner, T.; Smyth, F.; Biewer, G.; Shevlin, M.; Ferreira, M.A.V.; Toboso Martín, M.; Rodríguez Díaz, S.; Šiška, J.; Latimier, C.; Kanova, S (2015). "Paving the way through mainstream education: the interplay of families, schools and disabled students", en Research Papers in Education, vol. 30, n. 4, pp. 411-426. Disponible en: http://www.tandfonline.com/doi/full/10.1080/02671522. 2014.989175

Bynce, Y., Oliver, M y Barnes, C. (1991). Equal rights for disabled people: The case for a new law. Institute for Public Policy Research, Londres. 
Chicote, J. C.; Díaz, E.; Ferreira, M.A.V. (2014). “Adoption of assistive technology by persons with auditory and visual disability: A longitudinal revision in Spain considering Contextual Factors"; en New research on assistive technologies: Uses and limitations. Nova Science Publishers, Nueva York. Disponible en: https://www.novapublishers.com/catalog/product_info.php?products_id=51470 \&osCsid=be410bfe49edb2ea0ea3239891d33244

Conde, F (1993). "Los métodos extensivos e intensivos en la investigación social de las drogodependencias", en VV.AA.: Las drogodependencias: Perspectivas sociológicas actuales. Ilustre Colegio Nacional de Doctores y Licenciados en Ciencias Políticas y Sociología, Madrid.

Díaz Velázquez, E. (2009). "Un enfoque sociológico en el estudio de la discapacidad: ciudadanía, identidad y diversidad funcional", en Nova Melle, P y del Pino Artacho, J. A. (eds.). Sociedad y Tecnología ¿Qué futuro nos espera? Asociación Madrileña de Sociología, Madrid, pp. 13-20.

Ferrante, C.; Ferreira, M. A. V. (2008). "Cuerpo, discapacidad y trayectorias sociales: dos estudios de caso comparados", en Revista de Antropología Experimental, n. 8. pp. 403-428. Disponible en: http://www.ujaen.es/huesped/rae/articulos 2008/29ferrante08.pdf

Ferreira, M. A. V. (2008). "Una aproximación sociológica a la discapacidad desde el modelo social: Apuntes caracteriológicos", en Revista Española de Investigaciones Sociológicas (REIS), n. 124, pp. 141-174. Disponible en: http://www.reis.cis.es/REIS/PDF/REIS_124_051222873458779.pdf

Ferreira, M. A. V. (coord.) (2010a). "Por una sociología de la discapacidad", en Política y Sociedad, vol. 47, n. 1. Disponible en: http://revistas.ucm.es/index.php/ POSO/issue/view/POSO101013/showToc

Ferreira, M. A. V. (2010b). "Discapacidad y corporalidad: una aproximación genealógica"; en Brenda A y Bustos y Martínez Sánchez, M. L. (coord.). Cuerpo y discapacidad: Perspectivas Latinoamericanas. Universidad Autónoma de Nuevo León - Asociación Latinoamericana de Sociología, México, pp. 55-89. Disponible en: http://www.mferreira.es/Documentos_nuevo/ontogenesis_disca.pdf

Ferreira, M. A. V. y Díaz Velázquez, E. (2009). "Discapacidad, estratificación social y nuevas tecnologías de la información”, en Política y Sociedad, vol. 46, n. 1-2, pp. 235-258.

Ferreira, M. A. V. y Ferrante, C. (2010). "El habitus de la discapacidad: la experiencia corporal de la discapacidad en un contexto económico periférico", en Política y Sociedad, vol. 47, n. 1, pp. 87-104.

Ferreira, M. A. V. y Toboso Martín, M. (2014). "Cuerpo, emociones y discapacidad: La experiencia de un "desahucio" vital", en Revista Latinoamericana de Estudios sobre Cuerpo, Emociones y Sociedad (RELACES), n. 14, pp. 22-33.

Finkelstein, V. (1980). Attitudes and Disabled People: Issues for Discussion. World Rehabilitation Fund, Nueva York.

Fisher, K. (2010). Pushing the right buttons: Disabled students in higher education \& their use of assistive technology. En: http://pf7d7vi404s1dxh27mla5569. wpengine.netdna-cdn.com/files/library/Fisher-K-Fisher-Dissertation-2010.pdf

García Selgas, F. (2014). "Para modelizar la fluidez social II: De la cartografía a los modelos complejos de fluidez social", en Atenea Digital: Revista De Pensamiento e Investigación Social, vol. 14, n. 3, pp. 173-197. Disponible en: https://dialnet.unirioja.es/descarga/articulo/4869613.pdf 
Gatti, G. y Casado Aparicio, E. (2001). "Viaje por las fronteras del campo sociológico: Una cartografía de la investigación social", en Política y Sociedad, n.36; pp. 151-171. Disponible en: http://revistas.ucm.es/index.php/POSO/article/ viewFile/poso0101130151a/24423

Gleson, B. (1999). Geographies of Disability. Routledge, Londres.

Grasso, M., Pagola, L. y Zanotti, A. (2017). "Políticas de inclusión digital en Argentina. Usos y apropiaciones dentro y fuera de la escuela", en Pixel-Bit: Revista De Medios Y Educación, n. 50, pp. 95-107.

Huete, A., Sola, A.; Lara, P. y Díaz Velázquez, E. (2010). El impacto de la crisis económica en las personas con discapacidad y sus familias. Ediciones CincaComité Español de Representantes de Personas con Discapacidad, Madrid.

Ibáñez, J. (1985). Del algoritmo al sujeto: Perspectivas de la investigación social. Siglo XXI, Madrid.

Liberty (1994). Access denied - human rights and disables people. National Council to Civil Liberties, Madrid.

Lizarazo, S. M., Glasseman, L. D. y Ramírez, M. S. (2015). “Desarrollo de la apropiación tecnológica con recursos educativos abiertos para el aprendizaje en la educación primaria rural", en Edutec: Revista Electrónica de Tecnología Educativa, n. 51, pp. 1-14.

Mannaseh. (2009). Cultural oppression and emotional distress: Finding the links. En línea: http://pf7d7vi404s1dxh27mla5569.wpengine.netdna-cdn.com/files/ library/massaneh-CManasseh-anasseh-MA-Disability-Studies-DistanceLearning-Dissertation.pdf

Morris, J. (1991). Pride against prejudice: Transforming attitudes to disability. The Women's Press, Londres.

Ministerio de Sanidad. (2014). Plan de Acción de la Estrategia Española sobre Discapacidad 2014-2020. En línea:

https://www.msssi.gob.es/ssi/discapacidad/docs/plan_accion_EED.pdf_

Oliver, M. (1990). The politics of Disablement: a Sociōogical Approach. Palgrave Macmillan, Londres.

Oliver, M. (1998). “¿Una sociología de la discapacidad o una sociología discapacitada?", en Barton, L. (comp.). Discapacidad y Sociedad. Morata, Madrid.

Oliver, M. (2002). "Emancipatory research: A vehicle for social transformation or policy development", $1^{\text {st }}$ Annual Disability Research Seminar, NDA-CDS. Disponible en: http://www.leeds.ac.uk/disability-studies/archiveuk/Oliver/ Mike\%27s\%20paper.pdf.

ONU (2006): Convención Internacional sobre los Derechos de las personas con Discapacidad (y Protocolo Facultativo). En línea: http://www.un.org/disabilities/documents/convention/convoptprot-s.pdf

Rodríguez Caamaño, M. J. y Ferreira, M.A.V. (2006). "Sociología de la discapacidad: Una propuesta teórica crítica", en Nómadas, Revista Crítica de Ciencias Sociales y Jurídicas, n. 13. Disponible en: http://pendientedemigracion.ucm.es/ info/nomadas/13/ferreiracaamano.pdf

Rodríguez Díaz, S y Cano Esteban, A. (2015). Discapacidad y políticas públicas: La experiencia real de los jóvenes con discapacidad en España. Ed. Catarata, Madrid.

Rodríguez Díaz, S y Ferreira M. A. V. (2010). "Desde la discapacidad hacia la diversidad funcional: Un ejercicio de dis-normalización”, en Revista Internacional de 
Sociología, vol. 68, n. 2, pp. 289-309. Disponible en: http://www.um.es/discatif/documentos/SRDyMAVF_RIS.pdf

Romero, A y Castaño, C. M. (2016). "Prevenir las dificultades lectoras: Diseño y evaluación de un software educativo", en Píxel-Bit: Revista de Medios y Educación, n. 49, pp. 207-223.

Sen, A. (1985). Commodities and capabilities. Elsevier Science. Amsterdam.

Sen, A. (1993). "Capability and Well-Being", en Nussbaum, M. C y Sen, A. (eds.) The quality of life. Oxford University Press, New York, pp. 30-53.

Shakespeare, T. (1993). "Disabled people's self-organization: A new social movement?", en Disability, Handicap \& Society, vol. 8, n. 3, pp. 249-264

Sheldon, A. (2003). Disabled People and Communication Systems in the Twenty First Century. En línea: http://pf7d7vi404s1dxh27mla5569.wpengine.netdnacdn.com/files/library/Sheldon-thesis2viv2.pdf

Sheldon, A. (2003). Changing Technology. En línea: http://pf7d7vi404s1dxh27 mla5569.wpengine.netdna-cdn.com/files/library/Sheldon-chapter-for-alison.pdf

Terrazas, M., Sánchez, S y Becerra, M. T. (2016). "Las TIC como herramienta de apoyo para personas con Trastorno del Espectro Autista (TEA)", en Revista de Educación Inclusiva, vol. 9, .n. 2, pp. 102-136.

Toboso Martín, M. (2011). "Rethinking disability in Amartya sen's approach: ICT and equality of opportunity"', en Ethics and Information Technology, vol. 13, n. 2, pp. 107-118.

Toboso Martín, M. (2013). "De los discursos actuales de la discapacidad en España", en Política y Sociedad, vol. 50, n. 2. pp. 681-706. Disponible en: $\mathrm{http} / / /$ revistas.ucm.es/index.php/POSO/article/viewFile/39007/40784

Toboso Martín, M y Rogero García, J. (2012). "Diseño para todos en la investigación social sobre personas con discapacidad", en Revista Española de Investigaciones Sociológicas, n. 140, pp. 163-172.

Toboso Martín, M., Ferreira, M. A. V., Díaz Velázquez, E., Fernández-Cid Enríquez, M., Villa Fernández, N y Gómez De Esteban, C. (2012). "Sobre la educación inclusiva en España: Políticas y prácticas", en Intersticios: Revista Sociológica De Pensamiento Crítico, vol. 6, n. 1, pp. 279-295. Disponible en: http://www.intersticios.es/article/view/10048/6917

Topliss, E. (1982). Social Responses to Handicap. Longman, Harlow.

Unión Europea. (2010). Comunicado de la Unión Europea al Parlamento Europeo, a Consejo, al Comité Económico y Social Europeo y al Comité de las Regiones: Estrategia europea sobre discapacidad 2010-2020, un compromiso renovado para una Europa sin barreras. En línea: http://eur-lex.europa.eu/legal-content/ ES/ALL/?uri=CELEX\%3A52010DC0636 
